\title{
Correlation of serum albumin level with platelet count and aggregation in children with nephrotic syndrome
}

\author{
Andar Laura, Sri Sudarwati, Dany Hilmanto
}

\begin{abstract}
Background Nephrotic syndrome (NS) is the most common renal disease among children, and contributes to lifethreatening complications such as thromboembolic disease. Platelets are considered to be important agents in thrombotic events among NS patients. The gold standard assessment for platelet aggregation is the use of adenosine diphosphate (ADP) agonist, however, it is expensive and not accessible in smaller health facilities. Thus, other thrombosis parameters are needed. Previous studies suggested that low albumin increased the risk of thrombosis in NS patients.

Objective To assess for a possible correlation between albumin level and platelet count as well as platelet aggregation.

Methods This cross-sectional study was conducted in children with nephrotic syndrome who were admitted to the Pediatric Nephrology Department in Dr. Hasan Sadikin General Hospital, Bandung, West Java, from November 2017 to March 2018. Subjects were selected by consecutive sampling. Serum albumin, platelet count, and platelet aggregation were measured. Statistical analysis was conducted by Spearman's test.

Results A total of 32 patients participated in the study, with mean age of 109 (SD 7.4) months. Most subjects were male (56\%). Subjects' mean serum albumin level was 2.06 (SD 1.23) g/dL; mean platelet count was 453,062.5 (SD $187,443.90) / \mathrm{mm} 3$; and mean platelet aggregation values for ADP agonist concentrations of $10,5,2.5$, and $1 \mu \mathrm{M}$ were 86.8 (SD 8.63)\%, 82.4 (SD 15.33)\%, 66.6 (SD 24.90)\%, 34.95 (SD 31.69)\%, respectively. Partial correlation analysis revealed significant negative associations between albumin and platelet count as well as platelet aggregation assessed with $1 \mu \mathrm{M}$ of $\mathrm{ADP}$ concentration $(\mathrm{P}<0.001)$, with Spearman correlation coefficients of -0.641 and -0.634 , respectively. Conclusion Serum albumin level has a moderately negative correlation with platelet count and platelet aggregation value. [Paediatr Indones. 2019;59:7-12; doi: http://dx.doi. org/10.14238/pi59.1.2019.7-12 ].
\end{abstract}

Keywords: albumin; nephrotic syndrome; platelet aggregation value;platelet count

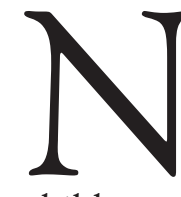

Tephrotic syndrome (NS) is the most common renal disease among children. A UK and US study stated the NS incidence as 2-7 new cases per 100,000 children annually, with prevalence around 12-16 cases per 100,000 children. ${ }^{1}$ In Indonesia, new cases of NS among children below 14 years of age were about 6 per 100,000 children annually in 1992. ${ }^{2}$ Nephrotic syndrome may contribute to lifethreatening complications during its course, including thromboembolic disease, such as deep vein thrombosis with or without pulmonary emboli, infection, as well as iatrogenic complications such as immunosuppression or bone density loss due to long-term use of steroids, and acute kidney injury which may lead to chronic kidney disease. ${ }^{1,3}$

Thromboembolic events are rare but generally fatal for NS patients. ${ }^{4,5}$ The risk of thrombosis in veins and arteries is caused by increased platelet count, platelet hyperaggregation, release of active substances, elevated platelet surface mediator

From the Department of Child Health, Universitas Padjadjaran Medical School/Dr. Hasan Sadikin General Hospital, Bandung, West Java, Indonesia.

Corresponding author: Andar Laura, Department of Child Health, Universitas Padjadjaran Medical School/Dr. Hasan Sadikin General Hospital, Jalan Pasteur no. 38, Bandung 40161, West Java, Indonesia. Email: andarlaura@gmail.com.

Submitted November 22, 2018. Accepted February 5, 2019. 
expression, and loss of low molecular weight proteins. Platelet are considered as an important agent of thrombosis among NS patients. ${ }^{6}$ The gold standard for platelet aggregation requires the use of adenosine diphosphate (ADP) agonists, which are dense granule degranulation products that directly induce platelet aggregation, unlike thrombin and collagen which only trigger ADP and TXA2 release. ${ }^{7}$ However, this examination may be affected by various medications such as NSAIDs, platelet receptor antagonists (Abciximab, Clopidogrel), glycoprotein IIb/IIIa inhibitor (Eptifibatide), phosphodiesterase inhibitor (Dipiridamol), anticoagulants (heparin, warfarin), diuretics, and vasodilators. ${ }^{8}$ The ADP agonist test also may require a larger blood specimen $(450 \mu \mathrm{L}$ of blood), can only be conducted in major laboratories, has a high predicted cost, and requires a long time to process the specimen. ${ }^{9}$ Other modalities with lower cost, higher availability, and easier procedures are needed to predict thrombosis events.

During relapse, serum albumin level decreases due to urinary excretion. Recent studies showed that low albumin level may elevate the venous thromboembolic rate by 2 to 5.8 times. ${ }^{10}$ Regarding the previous studies about the similar topic, this is the first study to assess for possible correlations between serum albumin level and other thrombosis parameters, such as platelet count and platelet aggregation value in pediatric NS patients.

\section{Methods}

This cross-sectional study was conducted in the Pediatric Inpatient Ward and Pediatric Outpatient Clinic, Dr. Hasan Sadikin General Hospital, Bandung, West Java, between November 2017 - March 2018. This study was approved by the Health Studies Ethics Committee at Dr. Hasan Sadikin General Hospital, Bandung.

Subjects were selected by consecutive sampling. Children diagnosed with NS and whose parents provided written informed consent were included in this study. Patients with previous thrombotic events or hepatic function disorders were excluded. Patients who underwent treatment with thrombolysis, fibrinolysis, or NSAIDs were also excluded.

Serum albumin level was measured by a UV-VIS
Spectrophotometer, while platelet count was assessed by Coulter counter. Platelet aggregation was measured as the amount of ADP agonist needed to induce aggregation, using the Helena AggRAM test kit and software.

Data processing and analysis was done with SPSS 24.0 for Windows. Collected data were noted on the research form, edited, and coded prior to data analysis. Spearman's test was used to analyze for correlations between serum albumin level and platelet count, as well as platelet aggregation. Results with $\mathrm{P}$ values $<0.05$ were considered to be statistically significant.

\section{Results}

A total of 32 patients participated in this study, with an age range of 17 to 210 months. Demographic characteristics are shown in Table 1. Most subjects were male and the mean patient age was 109 months (9 years and 1 month). Most patients were diagnosed as having resistant NS (21 subjects), followed by frequently- relapsing NS (6 subjects).

Table 1. Demographic characteristics of subjects

\begin{tabular}{lc}
\hline Characteristics & $(\mathrm{N}=32)$ \\
\hline Sex, $\mathrm{n}$ & \\
$\quad$ Male & 18 \\
Female & 14 \\
Age, months & \\
$\quad$ Median (range) & $102.5(17-210)$ \\
$\quad$ Mean (SD) & $109(57.4)$ \\
Diagnosis, $\mathrm{n}$ & \\
First episode of NS & 3 \\
$\quad$ Frequently-relapsing NS & 6 \\
$\quad$ Steroid-dependent NS & 2 \\
$\quad$ Steroid-resistant NS & 21 \\
\hline
\end{tabular}

Serum albumin level, platelet count, and platelet aggregation values are shown in Table 2. Data on serum albumin level and platelet aggregation by way of ADP concentrations of $5 \mu \mathrm{M}, 2.5 \mu \mathrm{M}$, and $1 \mu \mathrm{M}$ were not normally distributed $(\mathrm{P}<0.05)$, while data on platelet count and platelet aggregation value of $10 \mu \mathrm{M}$ ADP concentration were normally distributed. A typical linear pattern of platelet aggregation and ADP concentration were observed in this study.

Table 3 shows the correlation between variables 
Andar Laura et al.: Correlation of serum albumin with platelet count and aggregation in nephrotic syndrome

studied. We noted that age and albumin had a significant positive correlation $(\mathrm{r}=0.462 ; \mathrm{P}=0.008)$. However, age and platelet aggregation value showed a significant negative correlation $(\mathrm{r}=-0.353 ; \mathrm{P}=0.048)$ with ADP concentration of $1 \mu \mathrm{M}$. Serum albumin and platelet count had a significant negative association $(\mathrm{r}=-0.617 ; \mathrm{P}<0.001)$, while albumin and platelet aggregation value with $1 \mu \mathrm{M}$ ADP concentration had a significant negative association $(\mathrm{r}=-0.658$; $\mathrm{P}<0.001$ ), suggesting that lower serum albumin level was associated with increasing platelet count and platelet aggregation. Partial correlation analysis between serum albumin level and platelet count with age as confounding factor is shown in Table 4.

Serum albumin had negative correlations with platelet count and platelet aggregation values assessed with ADP concentration of $1 \mu \mathrm{M}$. According to Guilford correlation criteria, the correlation between serum albumin level and platelet aggregation value was moderate $(r>0.6)$.

Figure 1 shows the negative correlation between serum albumin and platelet count. There was a negative central trend with $\mathrm{R} \mathrm{Sq}$ linear of 0.392 . Hence, lower serum albumin was correlated with higher platelet count. Figure 2 shows the negative correlation between serum albumin and platelet aggregation. There was a negative central trend with $\mathrm{R}$ Sq linear of 0.357 . Hence, lower serum albumin was correlated with higher platelet aggregation.

\section{Discussion}

The majority of study subjects were male (18 boys; $56 \%$ ); the male: female ratio was 1.3:1. A previous study also noted that NS was more common in males compared to females. ${ }^{12}$ The mean age of subjects' was 109 months (9 years and 1 month old), which was

Table 2. Serum albumin level, platelet count, and platelet aggregation in pediatric NS patients

\begin{tabular}{lcrc}
\hline Variables & Mean (SD) & Median (range) & $P$ value \\
\hline Albumin serum, g/dL & $2.06(1.23)$ & $2.20(0.4-4.10)$ & $0.015^{*}$ \\
Platelet count, $/ \mathrm{mm}^{3}$ & $453,062.5(187,443.90)$ & $410,000(160,000-1,022,000)$ & 0.079 \\
Platelet aggregation assessed by ADP agonist, $\%$ & & & \\
$\quad 10 \mu \mathrm{M}$ & $86.8(8.63)$ & $87.55(68-99.70)$ & 0.080 \\
$5 \mu \mathrm{M}$ & $82.4(15.33)$ & $85.80(33.70-101.30)$ & $0.002^{*}$ \\
$2.5 \mu \mathrm{M}$ & $66.6(24.90)$ & $70.65(14.60-100.70)$ & $0.002^{*}$ \\
$1 \mu \mathrm{M}$ & $34.95(31.69)$ & $19.95(0.70-99.60)$ & $<0.001^{*}$ \\
\hline
\end{tabular}

Note: * Shapiro-Wilk test

Table 3. Analysis of possible correlations between study variables

\begin{tabular}{lcc}
\hline Variables & $\begin{array}{c}\text { Correlation } \\
\text { coefficient }\left(r_{s}\right)\end{array}$ & $P$ value \\
\hline Age and albumin & 0.462 & 0.008 \\
Age and platelet count & -0.253 & 0.163 \\
Age and platelet aggregation & & \\
$10 \mu \mathrm{M}$ & 0.156 & 0.395 \\
$5 \mu \mathrm{M}$ & 0.087 & 0.636 \\
$2.5 \mu \mathrm{M}$ & -0.023 & 0.899 \\
$1 \mu \mathrm{M}$ & -0.353 & 0.048 \\
Albumin and platelet count & -0.617 & $<0.001$ \\
Albumin and platelet aggregation & & \\
assissed by ADP agonist & & \\
$10 \mu \mathrm{M}$ & -0.139 & 0.448 \\
$5 \mu \mathrm{M}$ & -0.196 & 0.283 \\
$2.5 \mu \mathrm{M}$ & -0.281 & 0.120 \\
$1 \mu \mathrm{M}$ & -0.658 & $<0.001$ \\
Note: $r_{\mathrm{s}}=$ Rank Spearman correlation coefficient &
\end{tabular}

Table 4. Partial correlation analyses between serum albumin level and platelet count as well as platelet aggregation, with age as a confounding variable

\begin{tabular}{lcc}
\hline Correlation & $\begin{array}{c}\text { Correlation } \\
\text { coefficient }\end{array}$ & P value \\
\hline Albumin and platelet count & -0.641 & $<0.001$ \\
$\begin{array}{l}\text { Albumin and platelet aggregation } \\
\begin{array}{l}\text { assessed by ADP agonist } \\
\text { concentration of } 1 \mu \mathrm{M}\end{array}\end{array}$ & -0.634 & $<0.001$ \\
\hline
\end{tabular}


Andar Laura et al:: Correlation of serum albumin with platelet count and aggregation in nephrotic syndrome

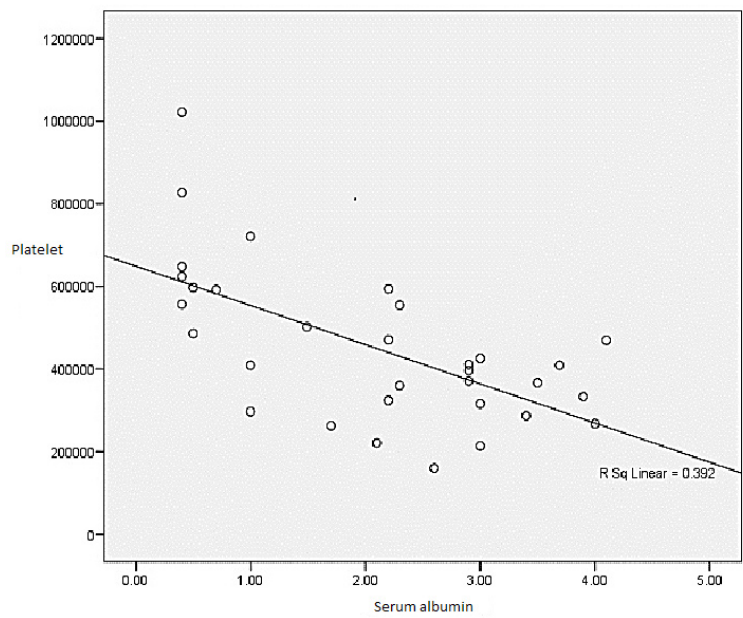

Figure 1. Correlation between serum albumin level and platelet count in pediatric NS patients

consistent with the theory that NS is more commonly found among school children and teenagers. Most of our subjects were diagnosed with steroid-resistant NS, which suggests that Dr. Hasan Sadikin General Hospital status is a top referral hospital.

Decreased serum albumin level is one of laboratory criteria needed to establish a diagnosis of nephrotic syndrome according the International Study of Kidney Disease in Children (ISKDC), with cutoff point of $2.5 \mathrm{~g} / \mathrm{dL} .{ }^{13}$ All subjects had at least +2 proteinuria on three urinalyses, based on urine dipstick measurement. Those with marked hypoalbuminemia were noted.

Several previous studies found the high platelet count among NS patients with high platelet count. ${ }^{14-17}$ Our subjects had a high mean platelet count of 453,062.50 (SD 187,443.90)/ $\mathrm{mm}^{3}$, ranging between $160,000-1,022,000 / \mathrm{mm}^{3}$, while $25 \%$ of patients had normal platelet count. An Indian study stated that thrombocytosis was always happened among NS patients, with mean (SD) platelet level of 307,000 $(49,099.5) / \mathrm{mm}^{3} .^{7}$ Mitall et al. found that platelet counts in steroid-sensitive NS and focal segmental glomerulosclerosis (FSGS) NS patients were higher than the control. Similarly, our subjects' mean platelet count was markedly high.

All subjects had received steroid medication, with a range of 1 day to 9 years, none of whom reported remission. Platelet count during remission and after cessation of therapy remained high,

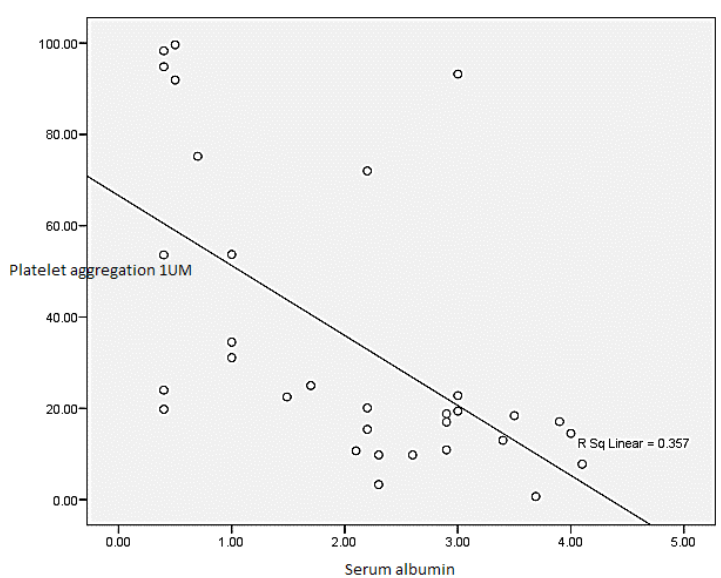

Figure 2. Correlation between serum albumin level and platelet aggregation value, assessed using ADP concentration of $1 \mu \mathrm{M}$ in pediatric NS patients

but returned to the normal range after long-term remission. ${ }^{16}$ The mechanism of elevated platelet count in NS patients is unclear, but several hypotheses suggest links to hypoalbuminemia, hypovolemia, and hypercholesterolemia. ${ }^{18}$

We noted hyperaggregation of platelet in our subjects. An Indian study in 2013 showed increased serum levels of collagen, ristocetin, arachidonic acid, and platelet aggregation rate as assessed by 5 and 2.5 $\mu \mathrm{M}$ ADP concentration tests in 29 pediatric NS patients. ${ }^{7}$ Patients with NS experience arachidonic acid (AA) release, which metabolizes into thromboxan A2, in turn inducing hyperaggregation of platelets. This rising aggregation has been connected to hypoalbuminemia, since albumin may inhibit platelet aggregation induced by arachidonic acid and its conversion.

Statistical analysis revealed that serum albumin level correlated in a linear manner with platelet count (correlation coefficient $0.641 ; \mathrm{P}<0.001$ ). Furthermore, statistical analysis of serum albumin level and platelet aggregation value with ADP concentration of $1 \mu \mathrm{M}$ revealed a moderate coefficient $(\mathrm{r}=-0.634 ; \mathrm{P}<0.001)$. Hence, serum albumin had negative correlations with those two variables. A previous retrospective study showed that NS patients with proteinuria and hypoalbuminemia had 8 times higher risk of a venous thromboembolic event. ${ }^{19}$ Another study on NS patients also reported that serum albumin level of 3-3.99 $\mathrm{g} / \mathrm{dL}$ would increase the thromboembolic event 
Andar Laura et al.: Correlation of serum albumin with platelet count and aggregation in nephrotic syndrome

risk by 1.5 times, while serum albumin level of 2.5-2.99 $\mathrm{g} / \mathrm{dL}$ would increase the thromboembolic event risk by 2.2 times, and serum albumin level below $2.5 \mathrm{~g} / \mathrm{dL}$ would increase the risk by 2.79 times. $^{11}$

This study had several limitations. The sample size was considered small for assessing correlations between these variables. We also did not analyze other factors that might have contributed to thromboembolic events, such as anticoagulation factors, fibrinolytic factors, factors V, VII, VIII, and X, von Willebrand factor, and total serum protein level. Further studies should be conducted with a larger sample size and include an evaluation of a practical diagnostic value of albumin for thromboembolic events.

In conclusion, serum albumin level negatively correlates with platelet count and platelet aggregation among pediatric NS patients.

\section{Conflict of Interest}

Authors stated that there was no competing interest in this study.

\section{Acknowledgements}

The authors received no specific grant from any funding agency in the public, commercial or not-for-profit sectors.

\section{References}

1. Eddy AA, Symons JM. Nephrotic syndrome in childhood. Lancet. 2003;362:629-39.

2. Wirya IGNW. Penelitian beberapa aspek klinis dan patologi anatomis sindrom nefrotik primer pada anak di Indonesia. Jakarta: FKUI; 1992. p.12-5.

3. Setty BA, O'Brien SH, Kerlin BA. Pediatric venous thromboembolism in the United States: a tertiary care complication of chronic diseases. Pediatr Blood Cancer. 2012;59:258-64.

4. Zaffanello M, Franchini M. Thromboembolism in childhood nephrotic syndrome: a rare but serious complication. Hematology. 2007;12:69-3.

5. Lau KK, Chan HH, Massicotte P, Chan AK. Thrombotic complications of neonates and children with congenital nephrotic syndrome. Curr Pediatr Rev. 2014;10:169-76.

6. Eneman B, Levtchenko E, van den Heuvel B, Van Geet C, Freson K. Platelet abnormalities in nephrotic syndrome.
Pediatr Nephrol. 2016;31:1267-79.

7. Mittal A, Aggarwal KC, Saluja S, Aggarwal A, Sureka B. Platelet functions and coagulation changes in Indian children with nephrotic syndrome. J Clin Diagn Res. 2013;7:164750.

8. Wirawan R. Nilai rujukan pemeriksaan agregasi trombosit dengan adenosin difosfat pada orang Indonesia dewasa normal di Jakarta. Maj Kedokt Indon. 2007;57:212-9.

9. Choi JL, Li S, Han JY. Platelet function tests: a review of progresses in clinical application. Biomed Res Int. 2014;2014:456569.

10. Lionaki S, Derebail VK, Hogan SL, Barbour S, Lee T, Hladunewich M, et al. Venous thromboembolism in patients with membranous nephropathy. Clin J Am Soc Nephrol. 2012;7:43-51.

11. Gyamlani G, Molnar MZ, Lu JL, Sumida K, KalantarZadeh K, Kovesdy CP. Association of serum albumin level and venous thromboembolic events in a large cohort of patients with nephrotic syndrome. Nephrol Dial Transplant. 2017;32:157-64

12. Andolino TP, Reid-Adam J. Nephrotic syndrome. Pediatr Rev. 2015;36:117-25.

13. Alatas H, Tambunan T, Trihono PP, Pardede SO. Konsensus tata laksana sindrom nefrotik idiopatik pada anak. $2^{\text {nd }}$ ed. Jakarta: Badan Penerbit Ikatan Dokter Anak Indonesia; 2012. p. $2-3$.

14. Eneman B, Freson K, van den Heuvel L, van Hoyweghen E, Collard L, Vande Walle J, et al. Pituitary adenylate cyclaseactivating polypeptide deficiency associated with increased platelet count and aggregability in nephrotic syndrome. J Thromb Haemost. 2015;13:755-67.

15. Andre E, Voisin P, Andre JL, Briquel ME, Stoltz JF, Martinet $\mathrm{N}$, et al. Hemorheological and hemostatic parameters in children with nephrotic syndrome undergoing steroid therapy. Nephron. 1994;68:184-91.

16. Tkaczyk M, Baj Z. Surface markers of platelet function in idiopathic nephrotic syndrome in children. Pediatr Nephrol. 2002;17:673-7.

17. Wasilewska AM, Zoch-Zwierz WM, Tomaszewska B, Biernacka A. Platelet-derived growth factor and platelet profiles in childhood nephrotic syndrome in children. Pediatr Nephrol. 2005;20:36-41.

18. Gulleroglu K, Yazar B, Sakalli H, Ozdemir H, Baskin E. Clinical importance of mean platelet volume in children with nephrotic syndrome. Ren Fail. 2014;36:663-5.

19. Hafni A, Hilmanto D, Rachmadi D, Sekarwana N. Trombocytosis in childhood relapsing nephrotic syndrome. Paediatr Indones. 2007;47:100-3. 
Andar Laura et al:: Correlation of serum albumin with platelet count and aggregation in nephrotic syndrome

20. Mahmoodi BK, ten Kate MK, Waanders F, Veeger NJGM, Brouwer JL, Vogt L, et al. High absolute risks and predictors of venous and arterial thromboembolic events in patients with nephrotic syndrome. results from a large retrospective cohort study. Circulation. 2008;117:224-30.

21. Limantara VL, Mudita IB, Suarta IK. Fibrinogen status in relapse and remission of childhood nephrotic syndrome. Paediatr Indones. 2006;46:149-153. 